Supplement of Biogeosciences, 18, 3219-3241, 2021 https://doi.org/10.5194/bg-18-3219-2021-supplement (c) Author(s) 2021. CC BY 4.0 License.

(c) (1)

Supplement of

\title{
Competing effects of nitrogen deposition and ozone exposure on northern hemispheric terrestrial carbon uptake and storage, 1850-2099
}

Martina Franz and Sönke Zaehle

Correspondence to: Martina Franz (mfranz@bgc-jena.mpg.de)

The copyright of individual parts of the supplement might differ from the article licence. 


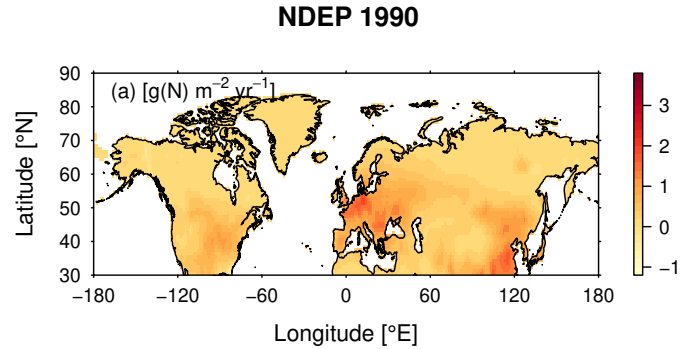

NDEP RCP8.5 2040

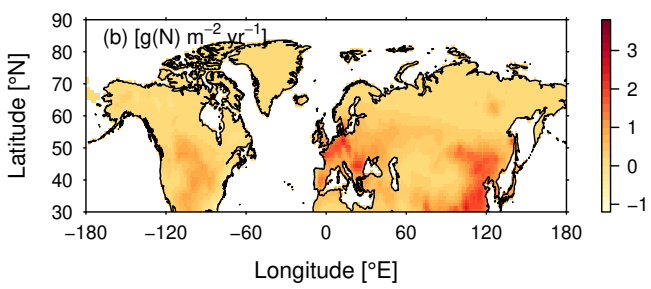

NDEP RCP8.5 2090

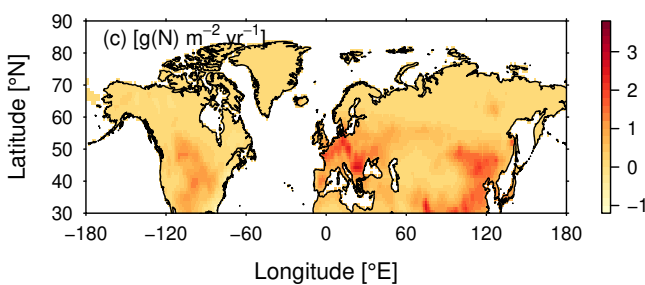

NDEP RCP2.6 2040

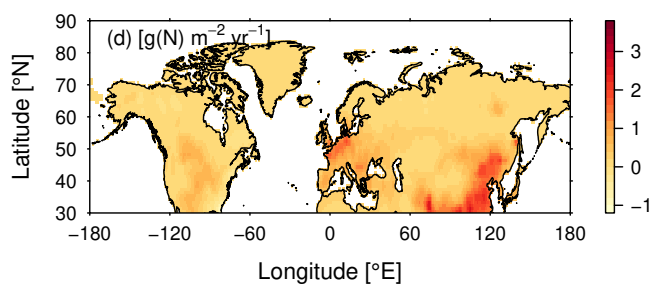

NDEP RCP2.6 2090

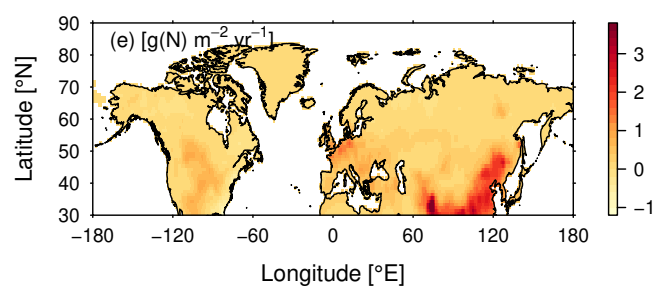

Figure S1. Mean simulated change in nitrogen deposition rates for the temperate and boreal Northern Hemisphere $\left(\geq 30^{\circ} \mathrm{N}\right)$ in the decades of the years of 1990, 2040 and 2090 compared to the decade of the year 1850, each according to the RCP2.6 and RCP8.5 emission scenario. 


\section{OZONE 1990}

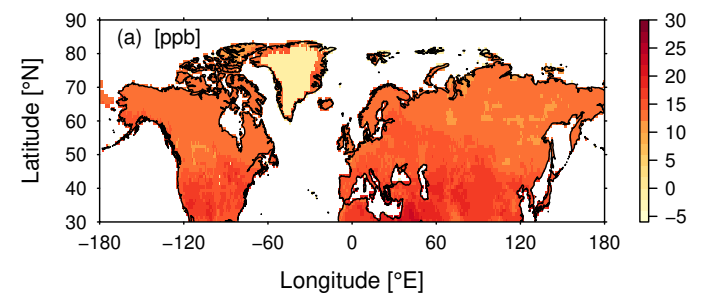

OZONE RCP8.5 2040

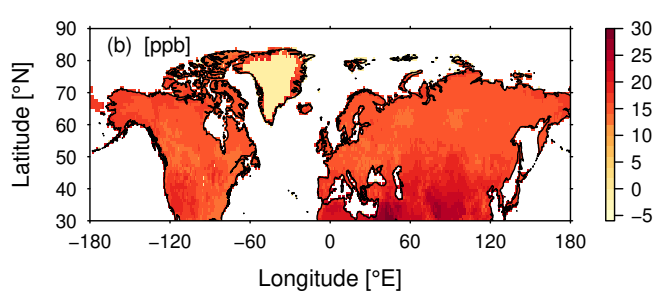

OZONE RCP8.5 2090

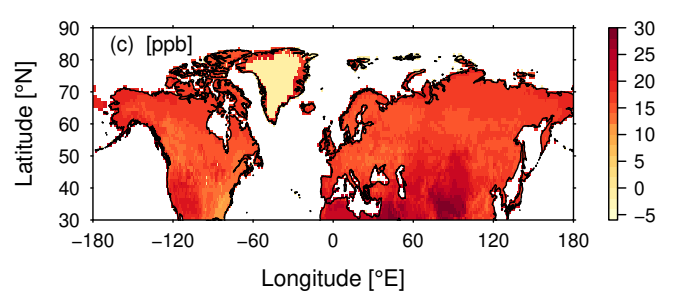

OZONE RCP2.6 2040

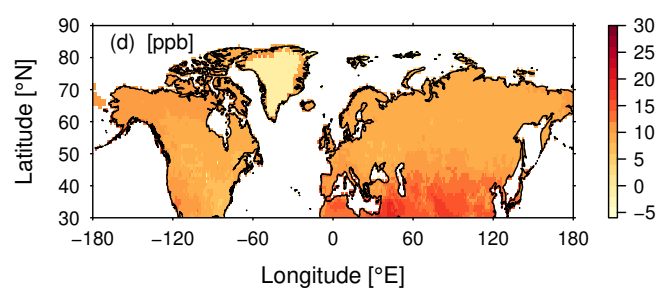

OZONE RCP2.6 2090

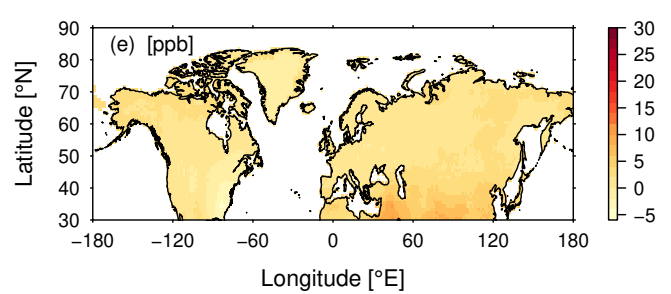

Figure S2. Mean simulated change in canopy level $\mathrm{O}_{3}$ concentration for the temperate and boreal Northern Hemisphere $\left(\geq 30^{\circ} \mathrm{N}\right)$ in the decades of the years of 1850, 1990, 2040 and 2090 compared to the decade of the year 1850, each according to the RCP2.6 and RCP8.5 emission scenario. 

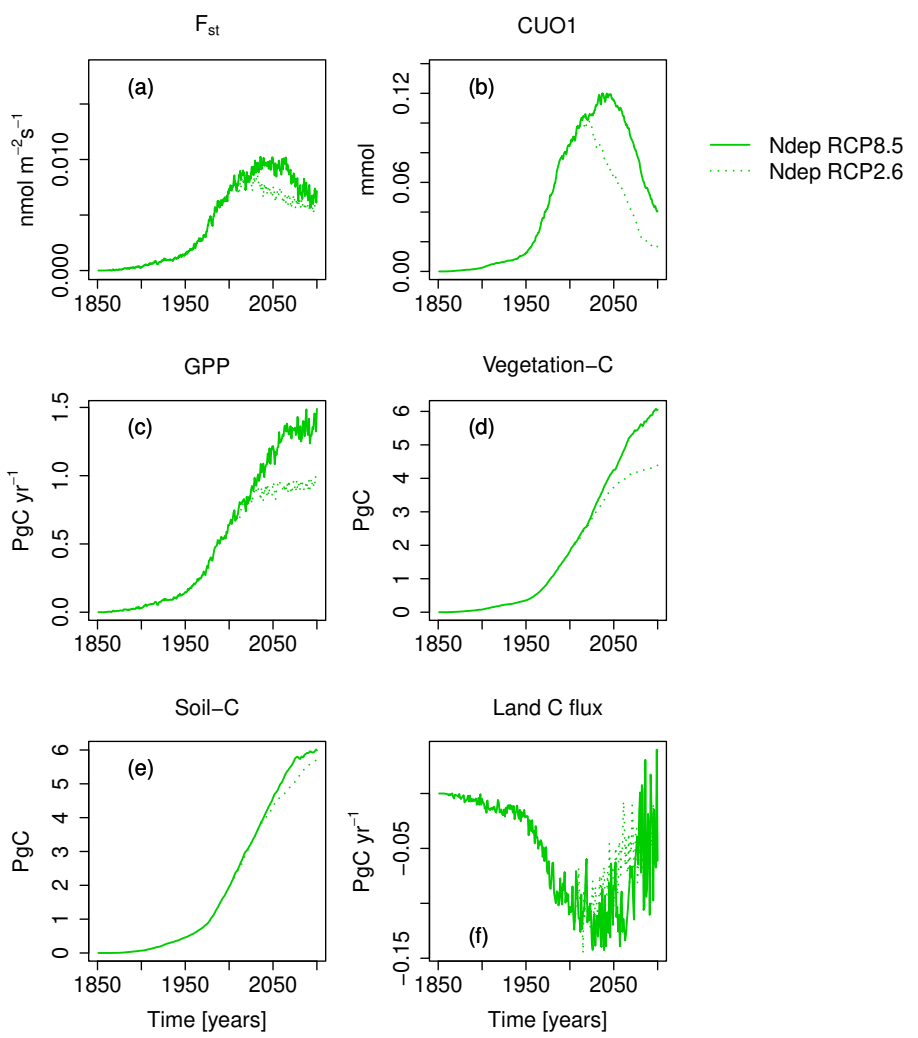

Figure S3. Nitrogen deposition induced absolute change in regional mean $\mathrm{O}_{3}$ uptake $\left(F_{s t}\right)$, mean cumulative $\mathrm{O}_{3}$ uptake above a flux threshold of $1 \mathrm{nmol} \mathrm{m}^{-2} \mathrm{~s}^{-1}$ (CUO1), summed GPP, total carbon biomass in vegetation (vegetation-C), summed carbon soil organic matter (soil-C), and summed land carbon flux (land C flux) compared to pre-industrial values in the simulation region. The nitrogen deposition induced change is calculated from the simulation runs S3 and S5 (see Tab. 2). Solid lines indicate results from simulations based on RCP8.5, dotted lines results from simulations based on RCP2.6. The effect of the seasonal cycle is smoothed by the application of a moving average of 12 months $(a, b)$. 

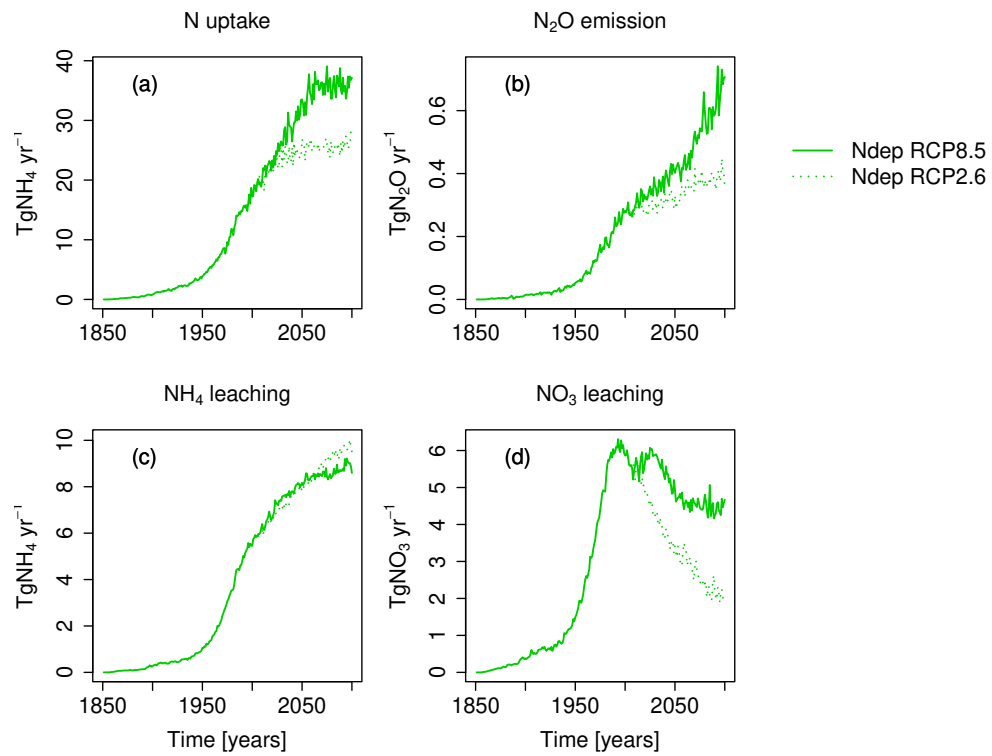

Figure S4. Nitrogen deposition induced absolute change in total $\mathrm{N}$ uptake by region, $\mathrm{N}_{2} \mathrm{O}$ emission, $\mathrm{NH}_{4}$ leaching and $\mathrm{N}_{2} \mathrm{O}$ leaching compared to pre-industrial values in the simulation region. The nitrogen deposition induced absolute change is calculated from the simulation runs S3 and S5 (see Tab. 2). Solid lines indicate results from simulations based on RCP8.5, dotted lines results from simulations based on RCP2.6. 

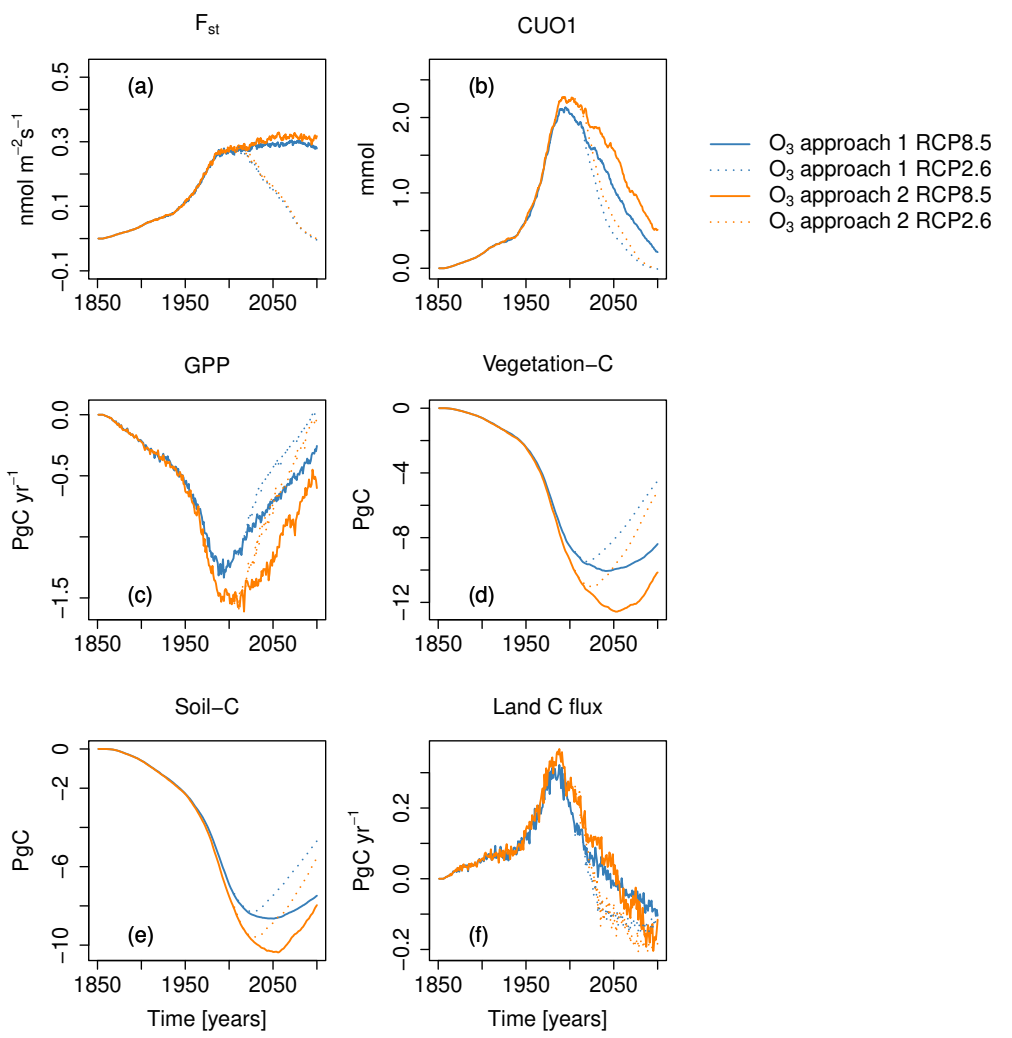

Figure S5. Ozone induced absolute change in regional mean $\mathrm{O}_{3}$ uptake $\left(F_{s t}\right)$, mean cumulative $\mathrm{O}_{3}$ uptake above a flux threshold of 1 $\mathrm{nmol} \mathrm{m}{ }^{-2} \mathrm{~s}^{-1}$ (CUO1), summed GPP, total carbon biomass in vegetation (vegetation-C) and summed carbon soil organic matter (soil-C) compared to pre-industrial values in the simulation region. Different colors indicate different approaches to calculate the $\mathrm{O}_{3}$ induced change from the factorial runs. Orange lines represent approach 1: (S2-S1)/S1, blue lines approach 2:(S5-S4)/S4. Solid lines indicate results from simulations based on RCP8.5, dotted lines results from simulations based on RCP2.6. The effect of the seasonal cycle is smoothed by the application of a moving average of 12 months. 


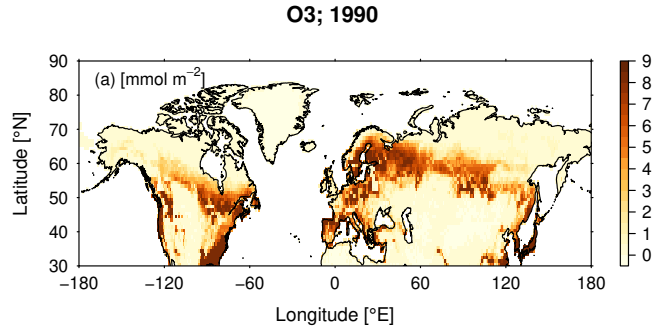

O3; 2040; RCP8.5

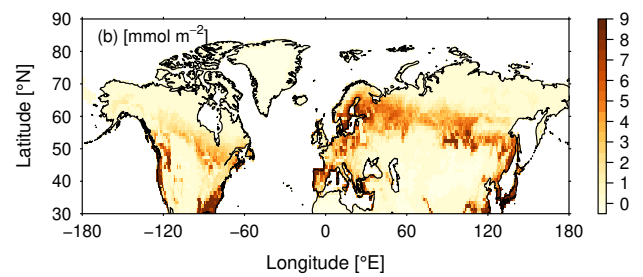

O3; 2090; RCP8.5

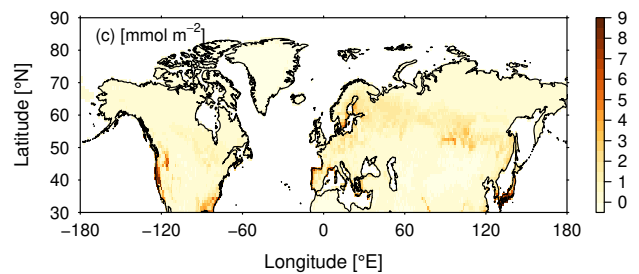

03; 2040; RCP2.6

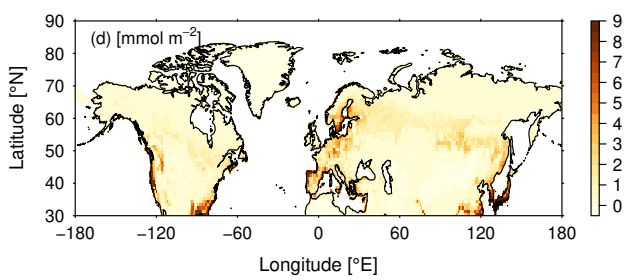

O3; 2090; RCP2.6

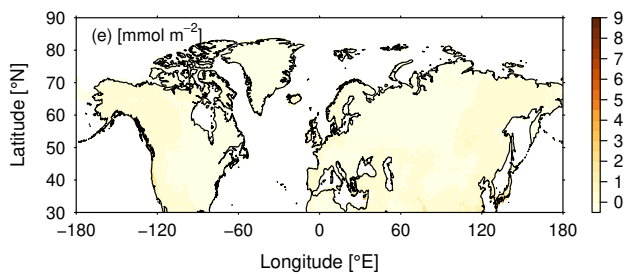

Figure S6. Absolute change in CUO1 compared to pre-industrial values induced by $\mathrm{O}_{3}$, calculated according to approach 2. Displayed are the decade 1990 (mean of the years 1990-1999), 2040 (mean of the years 2040-2049) and of 2090 (mean of the years 2090-2099). For the decades 2040 and 2090 results from simulations based on RCP8.5 and RCP2.6 are displayed. See Tab. 2 for details on the calculation of the $\mathrm{O}_{3}$ impact. 

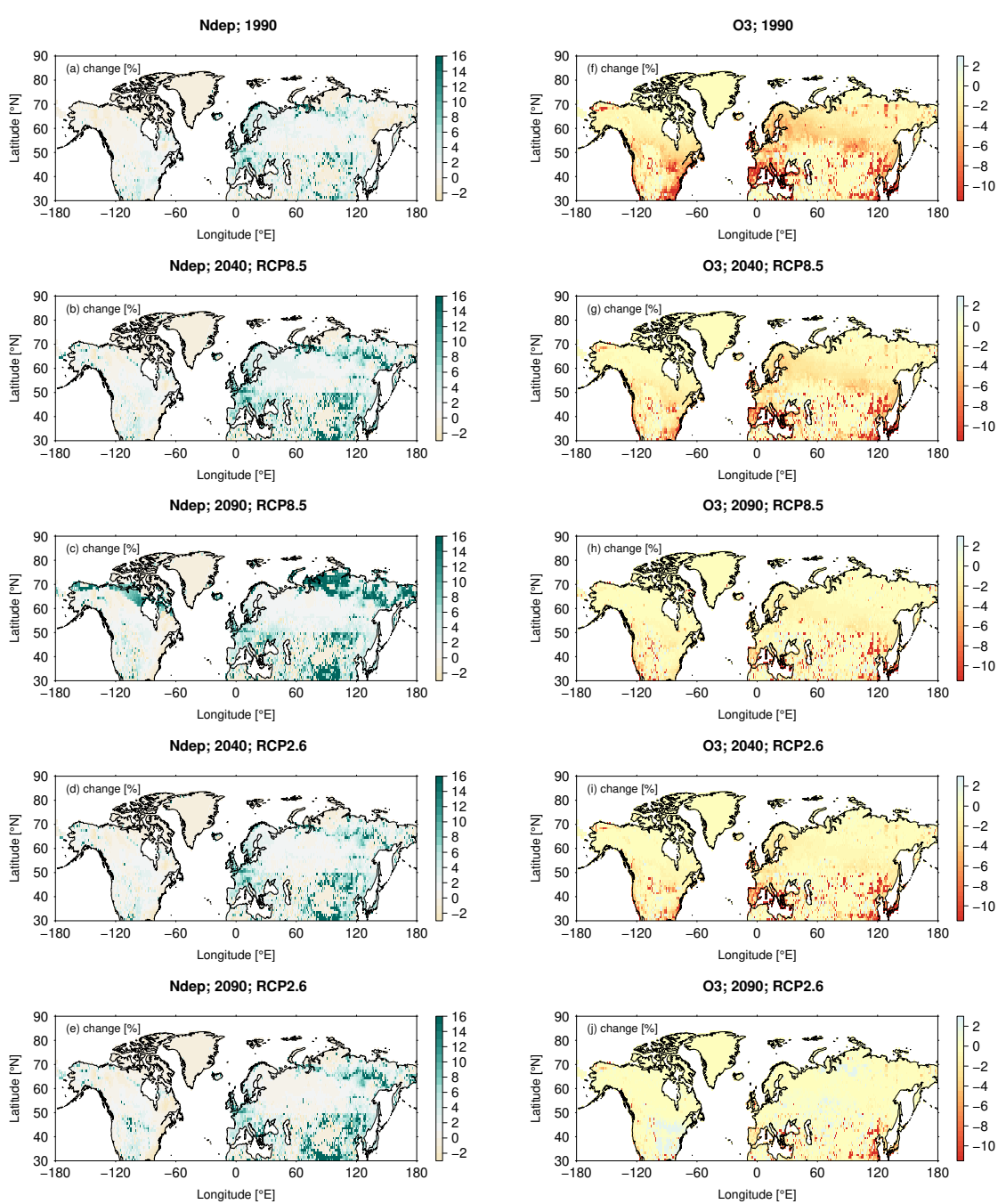

Figure S7. Relative change in GPP compared to pre-industrial values induced by nitrogen deposition (left column) and $\mathrm{O}_{3}$ calculated according to approach 2 (right column). The induced change in GPP is displayed for the decades 1990 (mean of the years 1990-1999), 2040 (mean of the years 2040-2049) and 2090 (mean of the years 2090-2099). For the decades 2040 and 2090 results from simulations based on RCP8.5 and RCP2.6 are displayed. See Tab. 2 for details on the calculation of the single drivers. 


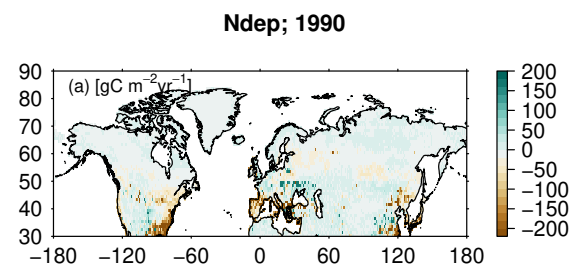

Ndep; 2040; RCP8.5

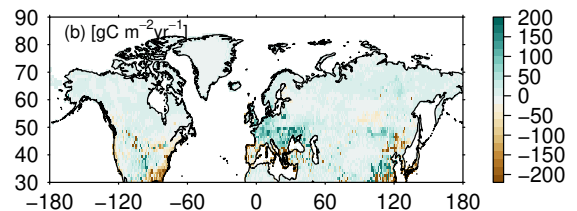

Ndep; 2090; RCP8.5

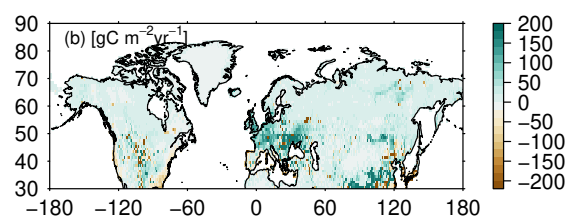

Ndep; 2040; RCP2.6

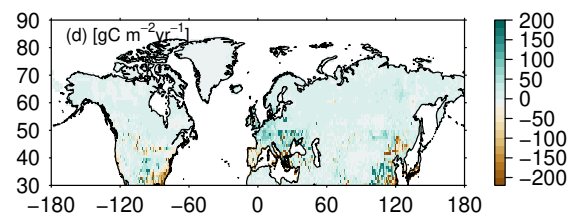

Ndep; 2090; RCP2.6

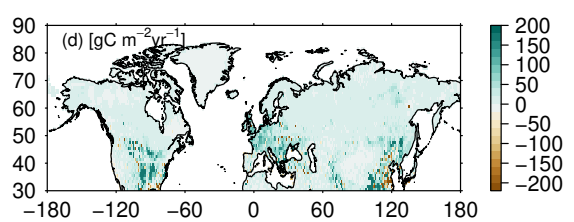

Figure S8. Combined absolute impact of nitrogen deposition and $\mathrm{O}_{3}$ calculated according to approach 2 on GPP compared to pre-industrial values. The induced change in GPP is displayed for the decades 1990 (mean of the years 1990-1999), 2040 (mean of the years 2040-2049) and 2090 (mean of the years 2090-2099). For the decades 2040 and 2090 results from simulations based on RCP8.5 and RCP2.6 are displayed. See Tab. 2 for details on the calculation of the single drivers. 

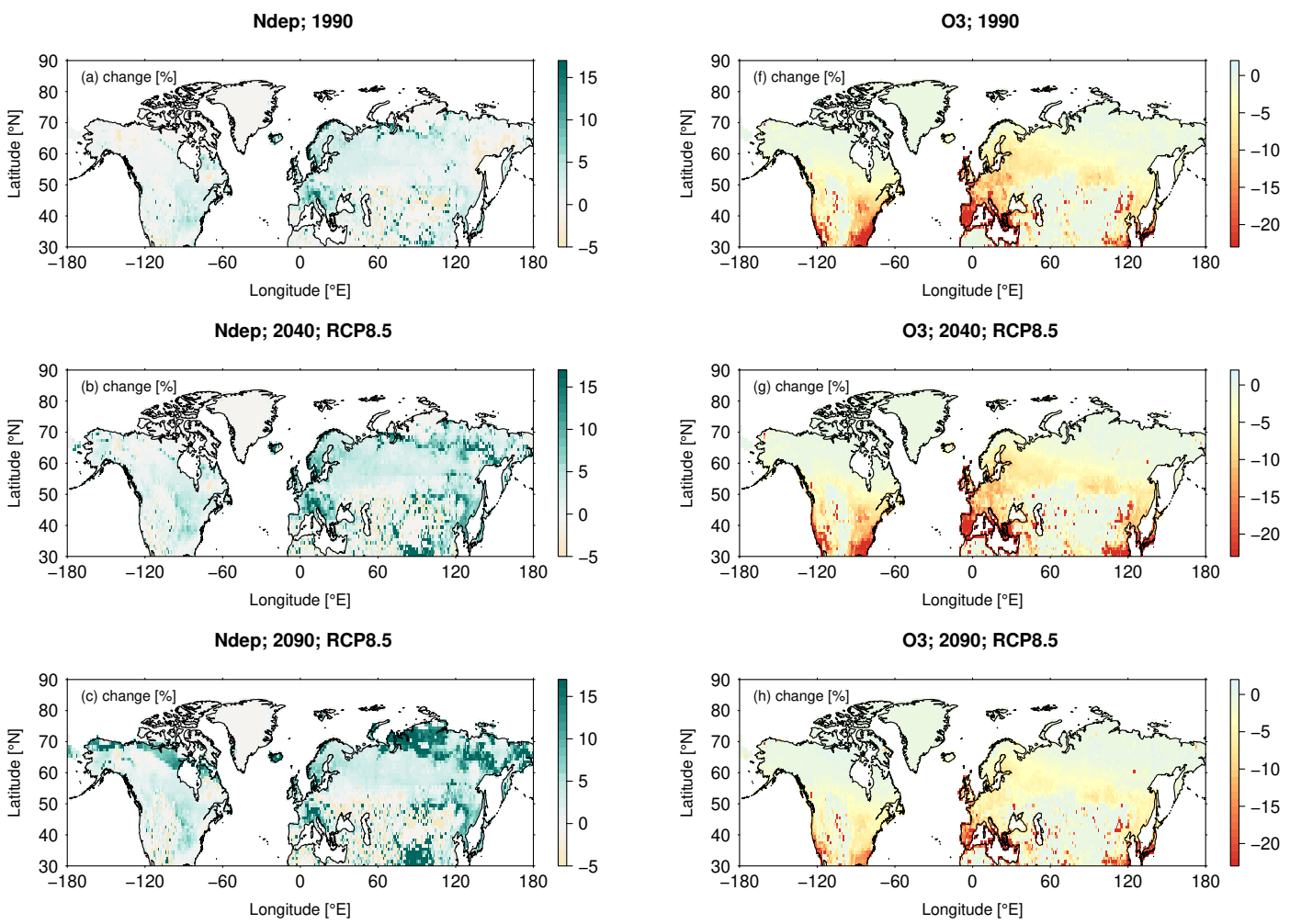

Ndep; 2040; RCP2.6

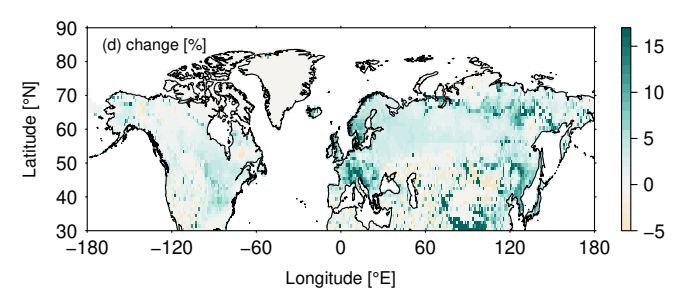

03; 2040; RCP2.6

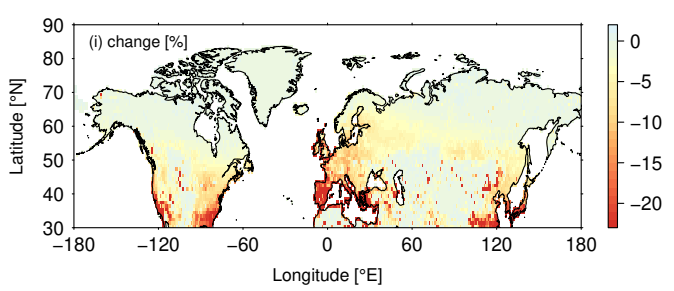

Ndep; 2090; RCP2.6
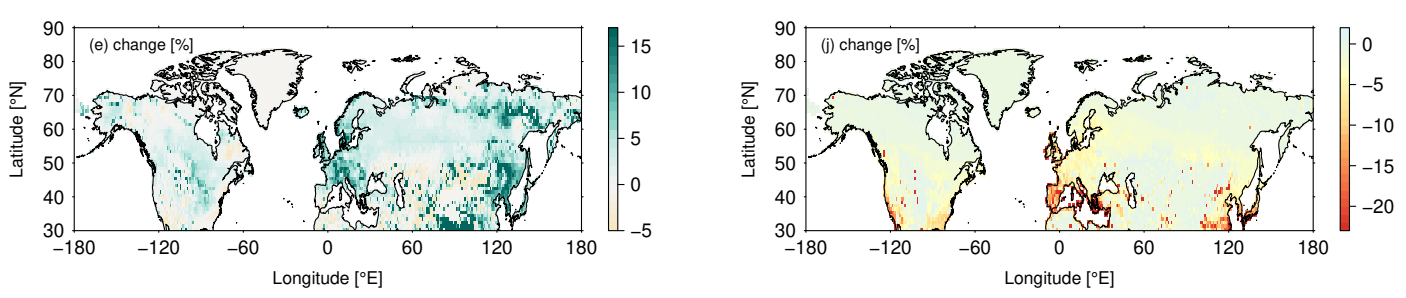

Figure S9. Relative change in the total carbon biomass in vegetation (vegetation-C) compared to pre-industrial values induced by nitrogen deposition (left column) and $\mathrm{O}_{3}$ calculated according to approach 2 (right column). The induced change in vegetation-C is displayed for the decades 1990 (mean of the years 1990-1999), 2040 (mean of the years 2040-2049) and 2090 (mean of the years 2090-2099). For the decades 2040 and 2090 results from simulations based on RCP8.5 and RCP2.6 are displayed. See Tab. 2 for details on the calculation of the single drivers. 
Table S1. The spread in the mean percent change displayed in Tab. 4 due to inter-annual variability, derived from error propagation of the yearly estimates in GPP, total carbon biomass in vegetation (vegetation-C), and land carbon flux (land $\mathrm{C}$ flux) induced by $\mathrm{O}_{3}$ during the decades of 1990 (1990-1999), 2040 (2040-2049) and 2090 (2090-2099). For $\mathrm{O}_{3}$ two values are displayed which refer to the two approaches to calculate the $\mathrm{O}_{3}$ impact.

\begin{tabular}{|c|c|c|c|c|c|c|}
\hline Region & Pollutant & 1990 & 2040 RCP8.5 & 2040 RCP2.6 & 2090 RCP8.5 & 2090 RCP2.6 \\
\hline \multicolumn{7}{|l|}{ GPP } \\
\hline NH30 & $\mathrm{O}_{3}$ & $\pm 0.17 ; \pm 0.14$ & $\pm 0.11 ; \pm 0.19$ & $\pm 0.09 ; \pm 0.22$ & $\pm 0.10 ; \pm 0.10$ & $\pm 0.10 ; \pm 0.08$ \\
\hline NH30 & Ndep & \pm 0.13 & \pm 0.18 & \pm 0.11 & \pm 0.20 & \pm 0.12 \\
\hline Europe & $\mathrm{O}_{3}$ & $\pm 0.25 ; \pm 0.33$ & $\pm 0.14 ; \pm 0.19$ & $\pm 0.14 ; \pm 0.24$ & $\pm 0.11 ; \pm 0.13$ & $\pm 0.04 ; \pm 0.08$ \\
\hline Europe & Ndep & \pm 0.26 & \pm 0.30 & \pm 0.21 & \pm 0.21 & \pm 0.12 \\
\hline USA & $\mathrm{O}_{3}$ & $\pm 0.41 ; \pm 0.39$ & $\pm 0.19 ; \pm 0.26$ & $\pm 0.17 ; \pm 0.30$ & $\pm 0.05 ; \pm 0.23$ & $\pm 0.20 ; \pm 0.17$ \\
\hline USA & Ndep & \pm 0.23 & \pm 0.19 & \pm 0.23 & \pm 0.30 & \pm 0.13 \\
\hline China & $\mathrm{O}_{3}$ & $\pm 0.95 ; \pm 0.76$ & $\pm 0.67 ; \pm 1.31$ & $\pm 0.45 ; \pm 1.02$ & $\pm 0.41 ; \pm 0.40$ & $\pm 0.43 ; \pm 0.44$ \\
\hline China & Ndep & \pm 0.23 & \pm 0.53 & \pm 0.23 & \pm 0.40 & \pm 0.59 \\
\hline \multicolumn{7}{|c|}{ Vegetation-C } \\
\hline NH30 & $\mathrm{O}_{3}$ & $\pm 0.38 ; \pm 0.40$ & $\pm 0.14 ; \pm 0.27$ & $\pm 0.15 ; \pm 0.17$ & $\pm 0.17 ; \pm 0.12$ & $\pm 0.19 ; \pm 0.18$ \\
\hline NH30 & Ndep & \pm 0.13 & \pm 0.15 & \pm 0.09 & \pm 0.08 & \pm 0.04 \\
\hline Europe & $\mathrm{O}_{3}$ & $\pm 0.34 ; \pm 0.42$ & $\pm 0.13 ; \pm 0.33$ & $\pm 0.19 ; \pm 0.21$ & $\pm 0.22 ; \pm 0.15$ & $\pm 0.18 ; \pm 0.24$ \\
\hline Europe & Ndep & \pm 0.15 & \pm 0.20 & \pm 0.11 & \pm 0.09 & \pm 0.05 \\
\hline USA & $\mathrm{O}_{3}$ & $\pm 0.62 ; \pm 0.50$ & $\pm 0.26 ; \pm 0.27$ & $\pm 0.27 ; \pm 0.29$ & $\pm 0.16 ; \pm 0.24$ & $\pm 0.28 ; \pm 0.25$ \\
\hline USA & Ndep & \pm 0.10 & \pm 0.07 & \pm 0.03 & \pm 06 & \pm 0.04 \\
\hline China & $\mathrm{O}_{3}$ & $\pm 1.63 ; \pm 1.86$ & $\pm 0.43 ; \pm 0.60$ & $\pm 0.23 ; \pm 0.32$ & $\pm 0.45 ; \pm 0.44$ & $\pm 0.44 ; \pm 0.48$ \\
\hline China & Ndep & \pm 0.13 & \pm 0.22 & \pm 0.19 & \pm 0.24 & \pm 0.21 \\
\hline \multicolumn{7}{|c|}{ Land C flux } \\
\hline NH30 & $\mathrm{O}_{3}$ & $\pm 4.28 ; \pm 4.48$ & $\pm 0.78 ; \pm 0.98$ & $\pm 2.45 ; \pm 2.07$ & $\pm 0.88 ; \pm 2.15$ & $\pm 3.87 ; \pm 7.86$ \\
\hline NH30 & Ndep & \pm 2.20 & \pm 1.42 & \pm 1.46 & \pm 2.04 & \pm 1.51 \\
\hline Europe & $\mathrm{O}_{3}$ & $\pm 12.48 ; \pm 14.84$ & $\pm 1.19 ; \pm 1.31$ & $\pm 3.57 ; \pm 4.70$ & $\pm 1.45 ; \pm 12.10$ & $\pm 8.66 ; \pm 11.30$ \\
\hline Europe & Ndep & \pm 13.34 & \pm 2.06 & \pm 1.69 & \pm 5.06 & \pm 2.10 \\
\hline USA & $\mathrm{O}_{3}$ & $\pm 8.60 ; \pm 12.22$ & $\pm 1.17 ; \pm 3.20$ & $\pm 2.13 ; \pm 6.93$ & $\pm 0.72 ; \pm 6.25$ & $\pm 5.30 ; \pm 12.86$ \\
\hline USA & Ndep & \pm 4.50 & \pm 3.85 & \pm 3.33 & \pm 4.95 & \pm 2.95 \\
\hline China & $\mathrm{O}_{3}$ & $\pm 13.23 ; \pm 25.46$ & $\pm 6.35 ; \pm 13.3$ & $\pm 6.85 ; \pm 11.77$ & $\pm 6.64 ; \pm 13.77$ & $\pm 16.81 ; \pm 14.57$ \\
\hline China & Ndep & \pm 15.81 & \pm 7.00 & \pm 4.89 & \pm 6.46 & \pm 8.29 \\
\hline
\end{tabular}

